\title{
IncRNA-ATB functions as a competing endogenous RNA to promote YAP1 by sponging miR-590-5p in malignant melanoma
}

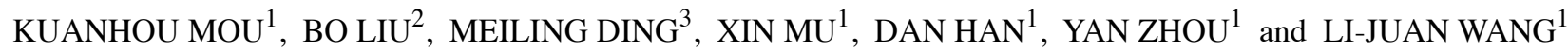 \\ ${ }^{1}$ Department of Dermatology, First Affiliated Hospital of Xi'an Jiaotong University, Xi'an, Shaanxi 710061; \\ ${ }^{2}$ Department of Dermatology, Yan'an Traditional Chinese Medicine Hospital, Yan'an, Shaanxi 716000; \\ ${ }^{3}$ State Key Laboratory of Cancer Biology, National Clinical Research Center for Digestive Disease, \\ Xijing Hospital of Digestive Diseases, Fourth Military Medical University, Xi'an, Shaanxi 710032, P.R. China
}

Received February 2, 2018; Accepted May 31, 2018

DOI: $10.3892 /$ ijo.2018.4454

\begin{abstract}
The critical long non-coding RNAs (lncRNAs) involved in the carcinogenesis and progression of malignant melanoma (MM) have not been fully investigated. In the present study, it was identified that IncRNA activated by transforming growth factor- $\beta$ (lncRNA-ATB) was upregulated in MM tissues and cells compared with benign nevus cells and human melanocytes, via comparative lncRNA screening from Gene Expression Omnibus datasets and reverse transcription-quantitative polymerase chain reaction analysis. Furthermore, IncRNA-ATB promoted the cell proliferation, cell migration, and cell invasion of MM cells in vitro, and tumor growth in vivo. It was additionally identified that lncRNA-ATB attenuated cell cycle arrest and inhibited cellular apoptosis in MM cells. Finally, it was demonstrated that lncRNA-ATB functions as a competing endogenous RNA (ceRNA) to enhance Yes associated protein 1 expression by competitively sponging microRNA miR-590-5p in MM cells. In conclusion, the present study revealed the expression and roles of IncRNA-ATB in MM, and indicated that lncRNA-ATB functions as a ceRNA to promote MM proliferation and invasion by sponging miR-590-5p.
\end{abstract}

\section{Introduction}

Malignant melanoma (MM) is one of the most aggressive forms of cutaneous neoplasm, the incidence of which has increased

Correspondence to: Dr Li-Juan Wang, Department of Dermatology, First Affiliated Hospital of Xi'an Jiaotong University, 277 Yanta West Road, Xi'an, Shaanxi 710061, P.R. China

E-mail: 6945216juan@163.com

Abbreviations: MM, malignant melanoma; lncRNA, long noncoding RNA; IncRNA-ATB, long noncoding RNA activated by transforming growth factor- $\beta$; YAP1, Yes associated protein 1

Key words: malignant melanoma, lncRNA-ATB, microRNA-590-5p, YAP1, competing endogenous RNA markedly in recent decades (1). An estimated 87,110 newly diagnosed MM cases and 9,730 MM-associated mortalities were predicted for 2017 in the United States (1). Despite the notable improvements in diagnosis and treatment made in recent years, the prognosis remains poor for patients diagnosed at the metastatic stage, with a median survival time of 6-9 months and a 5 -year survival rate of only $10 \%$ (2-4). Thus, it is necessary to establish effective biomarkers for the early diagnosis and efficient evaluation of prognosis following surgery.

Long non-coding RNAs (lncRNAs) are a class of transcripts $>200$ nucleotides in length with limited protein coding potential (5-7). Recently, studies have demonstrated that IncRNAs have multiple functions in a wide range of biological process, including proliferation (8), apoptosis (9), cell migration (10) and cell invasion (11). A novel regulatory mechanism whereby lncRNAs function as competing endogenous (ce)RNAs to sponge microRNAs (miRNAs) and regulate their downstream signaling pathways has been proposed and confirmed preliminarily (12-14). Although it has been reported that a number of IncRNA transcripts are involved in the carcinogenesis and development of MM (15-17), the miRNA sponge roles of lncRNAs in the modulation of cell proliferation and migration in MM remain unclear.

The present study screened for candidate lncRNAs responsible for the malignant phenotype of MM from the Gene Expression Omnibus (GEO) datasets. It was identified that long non-coding RNA activated by transforming growth factor (TGF)- $\beta$ (lncRNA-ATB) was the most markedly upregulated lncRNA in MM tissues and A375 cells compared with benign nevus cells and human melanocytes. The roles and underlying mechanism of lncRNA-ATB in the proliferation, apoptosis and invasion-metastasis cascade of MM cells were investigated and identified in vivo and in vitro.

\section{Materials and methods}

Cell culture. Highly invasive human MM A2058 cells, moderately invasive human MM A375 cells, normal epidermal melanocyte HEMa-LP cells, 293 and B16/F10 were obtained from the Cell Bank of the Chinese Academy of Sciences (Shanghai, China), where they were characterized by mycoplasma detection, DNA-fingerprinting, isozyme detection and 
cell vitality detection. A2058, A375, 293 and B16/F10 cells were cultured in Dulbecco's modified Eagle's medium (DMEM; Invitrogen; Thermo Fisher Scientific, Inc., Waltham, MA, USA) supplemented with 10\% fetal bovine serum (Hyclone; GE Healthcare Life Sciences, Logan, UT, USA) at $37^{\circ} \mathrm{C}$ in a humidified atmosphere of 95\% air and 5\% $\mathrm{CO}_{2}$. HEMa-LP cells were cultured in Medium 254 (Invitrogen; Thermo Fisher Scientific, Inc.) suplemented with human melanocyte growth supplement (Hyclone; GE Healthcare Life Sciences) at $37^{\circ} \mathrm{C}$ in a humidified atmosphere of $95 \%$ air and $5 \% \mathrm{CO}_{2}$.

Oligonucleotide transfection. pGMLV-lncRNA-ATB negative control (NC), pGMLV-lncRNA-ATB short hairpin (sh)RNA, miRNA (miR)-590-5p NC, miR-590-5p mimics and miR-590-5p inhibitors were purchased from GenePharma Co. Ltd. (Shanghai, China). The sequence for miR-590-5p was GAGCUUAUUCA UAAAAUGCAG; miR-NC was GUCCAGUGAAUUCCCAG; and miR-590-5p inhibitors was GACGUAAAAUACUUAUUC GAG. The IncRNA-ATB overexpressing plasmid was constructed by Shanghai GeneChem Co., Ltd. (Shanghai, China) using pCDNA3.1. An empty vector was used as the control (Shanghai GeneChem Co., Ltd.). When the cell confluence of A375 and A2058 cells reached 50-60\%, oligonucleotide transfections were performed using Lipofectamine ${ }^{\circledR} 2000$ (Thermo Fisher Scientific, Inc.), according to the manufacturer's protocol. Oligonucleotides $(50 \mathrm{nmol})$ were mixed with $5 \mu \mathrm{l}$ Lipofectamine ${ }^{\circledR} 2000$ in $500 \mu \mathrm{l}$ medium. The transfection solutions were added to each well containing $500 \mu \mathrm{l}$ medium. Following transfection, cell samples were collected at $48 \mathrm{~h}$ for further analyses.

RNA/miRNA extraction and reverse transcription-quantitative polymerase chain reaction (RT-qPCR) analysis. For lncRNA-ATB quantification, total RNA was extracted from the cells or tissues using TRI reagent (Sigma-Aldrich; Merck KGaA, Darmstadt, Germany), according to the manufacturer's protocol. RNA samples were reverse transcribed into cDNA using RT regeants (Takara Bio, Inc., Otsu, Japan) with lncRNA specific primers, and $\beta$-actin was used as internal loading controls. RT was performed at $45^{\circ} \mathrm{C}$ for $60 \mathrm{~min}$ and $70^{\circ} \mathrm{C}$ for $10 \mathrm{~min}$. SYBR Mix (Takara Bio, Inc.) was used to detect and quantify lncRNA-ATB and $\beta$-actin expression. For miR-590-5p quantification, total miRNA was extracted from the cells or tissues using the miRNeasy RNA isolation kit (Qiagen, Inc., Valencia, CA, USA), according to the manufacturer's protocol. Total miRNA samples $(1 \mu \mathrm{l} ; 1 \mu \mathrm{g} / \mu \mathrm{l})$ were reverse transcribed into cDNA using the miScript RT kit (Qiagen GmbH, Hilden, Germany) with miR-590-5p specific primers, and universal small nuclear U6 RNA was used as an internal loading control. An Applied Biosystems ${ }^{\mathrm{TM}}$ SYBR $^{\mathrm{TM}}$ Green dye miRNA RT-qPCR kit (Thermo Fisher Scientific, Inc.) was used to detect and quantify miR-590-5p and U6 expression. Data were analyzed with 7500 software v.2.0.1 (Applied Biosystems; Thermo Fisher Scientific, Inc.), with the automatic $\mathrm{Cq}$ setting for adapting baseline and threshold for Cq determination (18). Each sample was examined in triplicate. The primer sequences used in the present study are listed in Table I. RT-qPCR assays were performed under the following thermocycling conditions: $95^{\circ} \mathrm{C}$ for $5 \mathrm{~min}$, followed by 45 cycles of $95^{\circ} \mathrm{C}$ for $15 \mathrm{sec}, 60^{\circ} \mathrm{C}$ for $30 \mathrm{sec}$ and $72^{\circ} \mathrm{C}$ for $30 \mathrm{sec}$.
Western blotting. Cells were washed in PBS three times prior to the proteins being extracted. Cells were lysed using radioimmunoprecipitation assay buffer (JingCai Technologies, Inc., Xi'an, China) and the protein concentration was determined using the bicinchoninic acid method. Each protein sample $(30 \mu \mathrm{g})$ was denatured in SDS sample buffer and separated via $10 \%$ SDS-PAGE. Separated proteins were transferred to polyvinylidene fluoride membranes (EMD Millipore, Billerica, MA, USA), blocked with $5 \%$ bovine serum albumin (BSA; Beyotime Institute of Biotechnology, Haimen, China) for $2 \mathrm{~h}$ at room temperature, and incubated overnight with primary antibodies at $4^{\circ} \mathrm{C}$. Blotting was performed with primary antibodies against Yes associated protein 1 (YAP1; 1:300; cat. no. 14074; Cell Signaling Technology, Inc., Danvers, MA, USA). Goat anti-rabbit immunoglobulin horseradish peroxidase-linked $\mathrm{F}(\mathrm{ab}) 2$ fragments (1:5,000; cat. no. TA130071; OriGene Technologies, Inc., Beijing, China) were used as secondary antibodies for $2 \mathrm{~h}$ at room temperature. $\beta$-actin $(1: 4,000$; cat. no. ab8226; Abcam, Cambridge, UK) was used as a loading control. Blots were then washed three times (10 min/wash) in TBS-Tween-20 and developed using an enhanced chemiluminescence system (JingCai Technologies, Inc.). ImageJ (National Institutes of Health, Bethesda, MD, USA) was used to analyze the gray values of each blot.

Cell counting kit-8 (CCK-8) assay. A2058 cells transfected with lncRNA-ATB NC or lncRNA-ATB shRNA $24 \mathrm{~h}$ previously, and A375 cells transfected with empty vector or lncRNA-ATB overexpressing vector $24 \mathrm{~h}$ previously, were seeded in a 96-well culture plate at 2,000 cells/well. Each group was established in nine wells. CCK-8 reagents (cat. no. 40203ES60; Yeasen Biological Technology, Inc., Shanghai, China) were added into each well at 24, 48, 72, 96 and $120 \mathrm{~h}$ post-seeding, and each group was cultured for a further $50 \mathrm{~min}$ at $37^{\circ} \mathrm{C}$ in a humidified atmosphere of $95 \%$ air and $5 \% \mathrm{CO}_{2}$. The optical density values was measured at $490 \mathrm{~nm}$ using a microplate reader.

Flow cytometry. MM cells in a 6-well culture plate were harvested by trypsinization, and washed three times with PBS. For cellular apoptosis analysis, cells were suspended in $500 \mu \mathrm{l}$ binding buffer at a density of $2 \times 10^{6}$ cells $/ \mathrm{ml}$, and incubated with Annexin V-fluoroscein isothiocyanate and propidium iodide (PI; BD Biosciences, San Jose, CA, USA) for $15 \mathrm{~min}$ in the dark at room temperature. For cell cycle analysis, PI was added into A2058 cells tranfected with lncRNA-ATB NC or lncRNA-ATB, and A375 cells transfected with empty vector or IncRNA-ATB overexpressing vector, and incubated for $20 \mathrm{~min}$ in the dark at room temperature. Cellular apoptosis and the cell cycle were analyzed using a flow cytometer and Kaluza analysis software version 2.0 (both Beckman Coulter, Inc., Brea, CA, USA).

Cell migration and invasion. Cell migration and invasion capacity were measured in vitro using Transwell migration assays (EMD Millipore). A2058 cells transfected with lncRNA-ATB NC or lncRNA-ATB, and A375 cells transfected with empty vector or IncRNA-ATB overexpressing vector were suspended in DMEM with $10 \mathrm{~g} / \mathrm{l}$ BSA at a density of $5 \times 10^{5}$ cells $/ \mathrm{ml}$. Cell suspensions $(200 \mu \mathrm{l})$ were seeded in the 
Table I. Primers used for reverse transcription-quantitative polymerase chain reaction analysis.

\begin{tabular}{lll}
\hline Gene name & \multicolumn{1}{c}{ Forward primer $\left(5^{\prime} \rightarrow 3^{\prime}\right)$} & \multicolumn{1}{c}{ Reverse primer $\left(5^{\prime} \rightarrow 3^{\prime}\right)$} \\
\hline lncRNA-ATB & CTTCACCAGCACCCAGAGA & AAGACAGAAAAACAGTTCCGAGTC \\
$\beta$-actin & CGTCTTCCCCTCCATCGT & GAAGGTGTGGTGCCAGATTT \\
miR-590-5p & GGAATTCTTCAGTTGTAACCCAG & CGGGATCCTTGAGATGTCACCAA \\
U6 & CTCGCTTCGGCAGCACA & AACGCTTCACGAATTTGCGT
\end{tabular}

lncRNA-ATB, long non-coding RNA-activated by transforming growth factor- $\beta$; miR, microRNA.

upper chamber with membrane coated with (for the Transwell invasion assay) or without (for the migration assay) Matrigel (BD Biosciences). To attract the cells, $600 \mu \mathrm{l}$ DMEM with $10 \%$ serum was added to the bottom chamber. When the cells had been allowed to migrate for $24 \mathrm{~h}$ or to invade for $48 \mathrm{~h}$, the penetrated cells on the filters were fixed in dried methanol for $1 \mathrm{~min}$ and stained with $4 \mathrm{~g} / \mathrm{l}$ crystal violet for $10 \mathrm{~min}$ at room temperature. The numbers of migrated or invasive cells were determined from five random fields using a light microscope (Olympus Corporation, Tokyo, Japan) at x10 magnification.

Ethics statement. All animals were treated in accordance with the Guide for the Care and Use of Laboratory Animals, 1996, by the National Research Council (US) Institute for Laboratory Animal Research (19). Animal experiments were approved by and carried out according to the guidelines of the Ethics Committee of the First Affiliated Hospital of Xi'an Jiaotong University (Xi'an, China).

RNA pull-down assay. The full length lncRNA-ATB sequence or NC sequence was amplified by PCR kit (Takara Bio, Inc.) using a T7-containing primer. The following primer sequences were used: lncRNA-ATB forward, 5'-TCCCTGACTCCTCTA TGGCATCTGTGG-3'; lncRNA-ATB reverse, 5'-CCTTTGCT TCCTCTTTTCTCATCTACTC-3'. The thermocycling conditions were as stated above. The DNA fragments were cloned into pcDNA3.1. The restriction enzyme XhoI was used to linearize the plasmids. T7 RNA polymerase (Takara Bio, Inc.) and Biotin RNA Labeling Mix (Roche Diagnostics, Indianapolis, IN, USA) was used to make biotin-labeled RNAs that were reverse transcribed. The products were treated with RNase-free DNase I (Roche Diagnostics) and purified with an RNeasy Mini kit (Qiagen, Inc.), and subsequently mixed with RNA extract from A2058 cells and incubated at room temperature for $1 \mathrm{~h}$. The pull-down complexes were analyzed by RT-qPCR as previously stated following subsequent washes.

Tumor xenograft assays. All mice were housed and maintained under specific pathogen-free conditions at $18-22^{\circ} \mathrm{C}$, with $20 \%$ humidity, a 12-h light and 12-h dark cycle, with feeding ad libitum. All experiments were approved by the Animal Care and Use Committee of Xi'an Jiaotong University and performed in accordance with institutional guidelines. For the tumorigenesis assays, xenograft tumors were generated via subcutaneous injection of A2058 cells $\left(5 \times 10^{6}\right)$, including A2058 lncRNA-ATB NC and A2058 lncRNA-ATB shRNA, into the hind limbs of 18-20-g 4-6-week-old Balb/C female athymic nude mice (nu/nu; Animal Center of Xi'an Jiaotong University, Xi'an, China; total number, 10 mice; $n=5$ mice/group). Tumor size was measured using a vernier caliper. Tumor volume was determined by the following formula: $0.5 \times \mathrm{Ax} \mathrm{B}^{2}$, where A represents the diameter of the base of the tumor and $B$ represents the corresponding perpendicular value. After 35 days, the mice were sacrificed and the tumors were collected and weighed. For the lung colonization assay, B16/F10 cells $\left(5 \times 10^{6}\right)$, which included lncRNA-ATB NC-luciferase and lncRNA-ATB shRNA-luciferase were intravenously injected into 18-20-g 6-week-old female C57/B6 mice (total number, 10 mice; $n=5$ mice/group). Lung colonization was measured using Xenogen IVIS Kinetic imaging systems (PerkinElmer, Inc., Waltham, MA, USA) on days 0, 7 and 14 post-injection.

Luciferase assays. The putative binding sites of miR-590-5p for lncRNA-ATB were predicted using RNA hybrid(20) and miRDB (http://www.mirdb.org/). Two hundreds and ninety-three cells were seeded in a 96-well plate at $70 \%$ confluence. The lncRNA-ATB was cloned into pMir-Report (Ambion; Thermo Fisher Scientific, Inc.), yielding pMir-Report-lncRNA-ATB. Mutations were introduced in potential miR-590-5p binding sites using the QuikChange site-directed mutagenesis kit (Stratagene; Agilent Technologies, Inc., Santa Clara, CA, USA). miR-590-5p NC or mimics were transfected into 293 cells with $30 \mathrm{ng}$ wild-type (WT) or mutant (Mut) 3'-untranslated region (UTR) of lncRNA-ATB using Lipofectamine ${ }^{\circledR} 2000$, as previously stated. Cells were collected $48 \mathrm{~h}$ post-transfection, and luciferase assays were performed using a Photinus pyralis-Renilla reniformis dual luciferase reporter assay system, according to the manufacturer's protocol (Promega Corporation, Madison, WI, USA). The luciferase activity of each lysate was normalized to Renilla luciferase activity.

Statistical analysis. Differentially expressed lncRNAs were identified from the GEO database GSE3189 with false discovery rate $(\mathrm{FDR})<0.01$ and $\operatorname{logFCl}>1$ using the $\mathrm{R}$ package $(21)$. The raw $\mathrm{P}$-value was corrected using the Benjamini and Hochberg method (22) to circumvent the multi-test bias. A fold-change value $>2$ or $<0.25$ and FDR $<0.01$ were selected as cutoff criteria for differentially expressed lncRNAs. Statistical analysis was performed using SPSS statistical software (version 21.0; IBM Corp., Armonk, NY, USA). The differences in characteristics between two groups were examined by the Student's t-test. The differences in characteristics between three groups were examined by analysis of variance, and the least significant difference test was applied to detect the differences between 
each pair of groups. The correlation between miR-590-5p expression and YAP1 expression was analyzed by Pearson correlation analysis. All P-values were determined from two-sided tests, and $\mathrm{P}<0.05$ was considered to indicate a statistically significant difference. All experiments were repeated three times and the data are presented as the mean \pm standard deviation from three independent experiments.

\section{Results}

lncRNA-ATB is upregulated in MM cell lines. To elucidate the critical lncRNAs involved in the carcinogenesis and progression of MM, comparative lncRNA profiling was performed in $45 \mathrm{MM}, 18$ benign skin nevus cell (BN), and seven normal skin tissue specimens from the GEO dataset GSE3189 (23). Vectorgram analysis further identified that IncRNA-ATB was upregulated in MM specimens compared with BN (Fig. 1A and Table II). The volcano plot illustrates that the lncRNA-ATB expression level was $>4$-fold increased between cases and controls $(\mathrm{P}<0.001$; Fig. 1B). The significant upregulation of IncRNA-ATB was further confirmed using RT-qPCR in the human epidermal melanocyte cell line HEMa-LP and in MM cell lines (Fig. 1C).

Effects of IncRNA-ATB on the cell proliferation and apoptosis of $M M$ cells. To investigate the functional role of lncRNA-ATB in $\mathrm{MM}$ cells, gain- and loss-of function experiments were performed by transfecting an shRNA, shLncRNA-ATB, into the highly invasive MM cell line A2058 to knock down lncRNA-ATB expression (Fig. 1D; P<0.05). An lncRNA-ATB overexpressing plasmid was also transfected into the moderately invasive MM cell line A375 to stably overexpress lncRNA-ATB. CCK-8 assays indicated that the proliferation of A2058 cells transfected with shLncRNA-ATB was inhibited compared with that in the control (Fig. 2A). However, the proliferation of A375 cells transfected with the lncRNA-ATB overexpressing plasmid was enhanced compared with that in the control (Fig. 2B). Cellular apoptosis assays demonstrated that the percentage of early apoptotic cells increased in A2058 cells transfected with shLncRNA-ATB. Whereas, the percentage of early apoptotic cells decreased in A375 cells transfected with the lncRNA-ATB overexpressing plasmid (Fig. 2C and D).

Effects of lncRNA-ATB on the cell cycle distribution of MM cells. Cell cycle assays (Fig. 3) demonstrated that A2058 cells transfected with shLncRNA-ATB displayed a significant increase in the percentage of cells in the G1 phase and a decrease in the percentage of cells in the S phase (Fig. 3A and C). By contrast, the percentage of cells in the G1 phase decreased and the percentage of cells in the S phase increased in A375 cells transfected with the IncRNA-ATB overexpressing plasmid compared with that in the control (Fig. 3B and D).

Effects of lncRNA-ATB on the cell migration and invasion of $M M$ cells. The present study further investigated the effects of lncRNA-ATB on the cell migration and invasion of MM cells using Transwell assays (Fig. 4). The cell migration assays indicated a significant decrease in the number of migratory cells among A2058 cells transfected with shLncRNA-ATB
Table II. Top 30 lncRNAs upregulated in malignant melanoma.

\begin{tabular}{lc}
\hline lncRNA name & Log $_{2}$ fold-change \\
\hline LncRNA-ATB & 4.585437915 \\
Linc00662 & 3.029954694 \\
AC144652.1 & 3.057751736 \\
RP11-654D12.2 & 3.081628575 \\
PVT1 & 3.139985752 \\
PGM5-AS1 & 3.151644278 \\
MIR24-2 & 3.1683935 \\
SNHG19 & 3.233861413 \\
AC112721.2 & 3.301811151 \\
CTD-2066L21.3 & 3.34462291 \\
MIR378D2 & 3.356163777 \\
NUP50-AS1 & 3.420937034 \\
SNHG9 & 3.427925853 \\
AP006621.5 & 3.441188157 \\
LINC00973 & 3.515399942 \\
LUCAT & 3.567557456 \\
LINC01588 & 3.582647048 \\
YTHDF3-AS1 & 3.589774049 \\
BANCR & 3.678548044 \\
TUG1 & 3.78577717 \\
SPRY4-IT1 & 3.826319081 \\
H19 & 3.855857029 \\
HOXD-AS1 & 3.879582756 \\
FALEC & 3.881343407 \\
FTH1P3 & 3.915488817 \\
ILF3-AS1 10.18103013 \\
HOXA11-AS & 3.980602573 \\
HEIH & 4.004958111 \\
CCAT1 & 4.061621096 \\
MHENCR & \\
\hline & \\
\hline
\end{tabular}

Data from the Gene Expression Omnibus dataset GSE3189. IncRNA, long non-coding RNA.

compared with the control (Fig. 4A and C). By contrast, ectopic expression of IncRNA-ATB significantly increased the number of migratory A375 cells compared with the normal control (Fig. 4A and D). As expected, cell invasion assays also confirmed a decrease in the number of invasive cells among A2058 cells transfected with shLncRNA-ATB compared with the control (Fig. 4B and C). Ectopic expression of lncRNA-ATB significantly enhanced the invasive ability of A375 cells compared with the control (Fig. 4B and D).

Effects of lncRNA-ATB on the tumorigenic ability of MM cells. The effect of IncRNA-ATB on the tumorigenic ability of MM cells was detected in vivo. shLncRNA-ATB and luciferase were transfected into A2058 cells and tumorigenesis assays were performed in nude mice. Cells $\left(5 \times 10^{6}\right)$ were injected into the flanks of the nude mice. Tumor sizes were measured using the Xenogen IVIS Kinetic imaging system and Vernier calipers every 7 days. After 35 days, the mice 
A

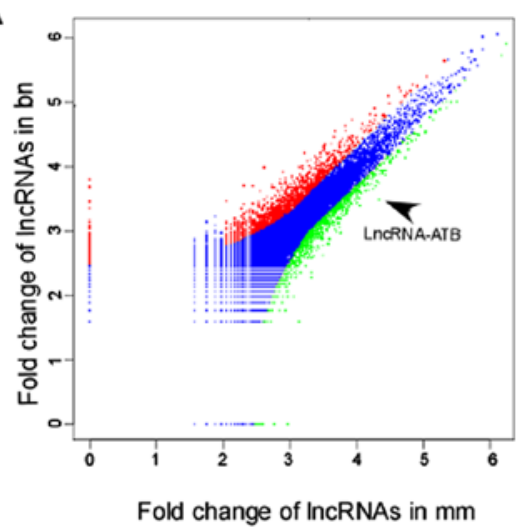

C

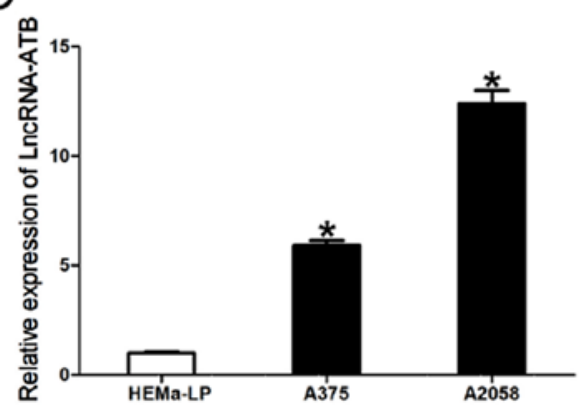

B

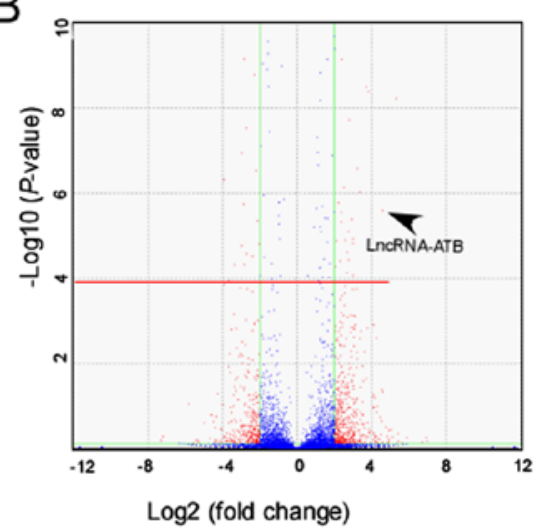

$\mathrm{D}$

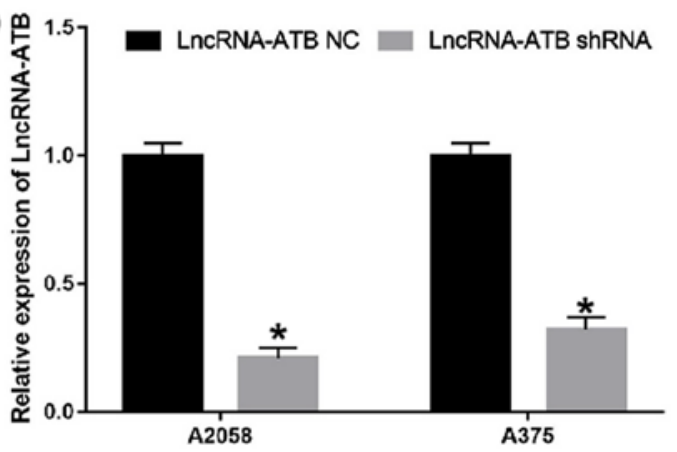

Figure 1. IncRNA-ATB is upregulated in MM cell lines of malignant melanoma. (A) Vectorgram analysis of lncRNAs in MM and BN specimens. The X-axis indicates the $\log _{2}$ fold-change in lncRNA expression in MM tissues, and the $y$-axis indicates the Log $\operatorname{lol}_{2}$ fold-change of lncRNA expression in BN tissues. Red, lncRNAs upregulated by $\geq 2$-fold in MM compared with BN. Green, lncRNAs upregulated by $\geq 2$-fold in BN compared with MM. Blue, lncRNAs upregulated by <2-fold in MM compared with BN or lncRNAs upregulated by <2-fold in BN compared with MM. Data from the GEO datasets (GSE3189): Differentially expressed lncRNAs from the GEO dataset GSE3189 with FDR $<0.01$ and $\log \mathrm{FCl}>2$ were identified using the R package. The raw P-value was corrected using the Benjamini and Hochberg method to circumvent the multi-test bias. A fold-change value $>2$ or $<0.25$ and FDR $<0.01$ were selected as cutoff criteria for

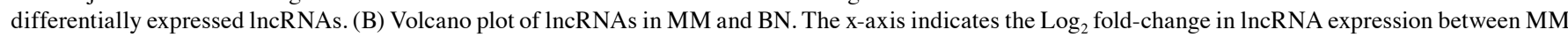
and BN tissues, while the $\mathrm{y}$-axis indicates the $\log _{10}$ of the adjusted P-value for each lncRNA. Values above the red line were identified to be statistically significant. $(\mathrm{P}<0.01)$ following application of the Benjamini and Hochberg method. lncRNA-ATB expression level was $>4$-fold increased between cases and controls $\left(\mathrm{P}<0.001\right.$ vs. BN). (C) Relative expression of lncRNA-ATB in human epidermal melanocytes and MM cells. ${ }^{*} \mathrm{P}<0.05$ vs. HEMa-LP cells. (D) Knockdown efficiency of lncRNA-shRNA in MM cells. Data are from three experiments and are presented as the mean \pm standard deviation. ${ }^{*} \mathrm{P}<0.05$ vs. respective lncRNA-ATB NC group (Student's t-test). MM, malignant melanoma; BN, benign nevi; lncRNA, long noncoding RNA; ATB, activated by transforming growth factor- $\beta$; GEO, Gene Expression Omnibus; FDR, false discovery rate; shRNA, short hairpin RNA; NC, negative control.

were sacrificed, and the tumors were collected and weighed. It was identified that shLncRNA-ATB had a significant tumor growth-inhibitory effect, causing significant reductions in tumor size (Fig. 5A and B) and weight (Fig. 5C) in the shLncRNA-ATB group compared with the control group. B16/F10 melanoma cells transfected with shLncRNA-ATB or controls were injected intravenously into C57/B6 mice, and lung colonization was assessed using the Xenogen IVIS200 System. It was identified that lung metastasis was inhibited in mice injected with B16/F10 cells transfected with shLncRNA-ATB, in comparison with the A2058 cells transfected with a control shRNA (Fig. 5D). Taken together, these results indicated that IncRNA-ATB was upregulated in MM cells, and that knockdown of lncRNA-ATB was able to repress cell proliferation, cell migration, cell invasion and tumor growth in vitro and in vivo.

lncRNA-ATB directly sponges miR-590-5p to upregulate YAPI expression. To examine the potential interaction between YAP1 and its targeting miRNA, miR-590-5p was identified as a potential targeting miRNA that has putative binding sites for lncRNA-ATB (Fig. 6A; data from RNA hybrid and miRDB), by searching in online bioinformatics databases. RT-qPCR assays revealed that miR-590-5p mimics and inhibitors were able to effectively upregulate and downregulate miR-590-5p expression, respectively, in $\mathrm{MM}$ cells (Fig. 6B; $\mathrm{P}<0.01$ ). The biotin-labeled pulldown assay indicated that IncRNA-ATB was able to directly pull down miR-590-5p, which suggested that lncRNA-ATB may directly and specifically sponge miR-590-5p (Fig. 6C). Accordingly, miR-590-5p expression was significantly increased in A2058 cells transfected with shLncRNA-ATB, and significantly downregulated in A375 cells transfected with the lncRNA-ATB overexpressing plasmid (Fig. 6D; $\mathrm{P}<0.05$ ). In addition, a dual-luciferase reporter assay was performed to verify whether lncRNA-ATB was the functional target of miR-590-5p. It was observed that miR-590-5p was able to reduce the relative luciferase activity of WT-LncRNA-ATB. Conversely, co-transfection of 293 cells with Mut-LncRNA-ATB and miR-590-5p resulted in a non-significant alteration in the relative luciferase activity (Fig. 6E). The RT-qPCR results showed that ectopic expression ofmiR-590-5pinA2058cellsinhibitedlncRNA-ATB expression, while IncRNA-ATB expression was upregulated in A375 cells transfected with miR-590-5p inhibitors (Fig. 6F). 

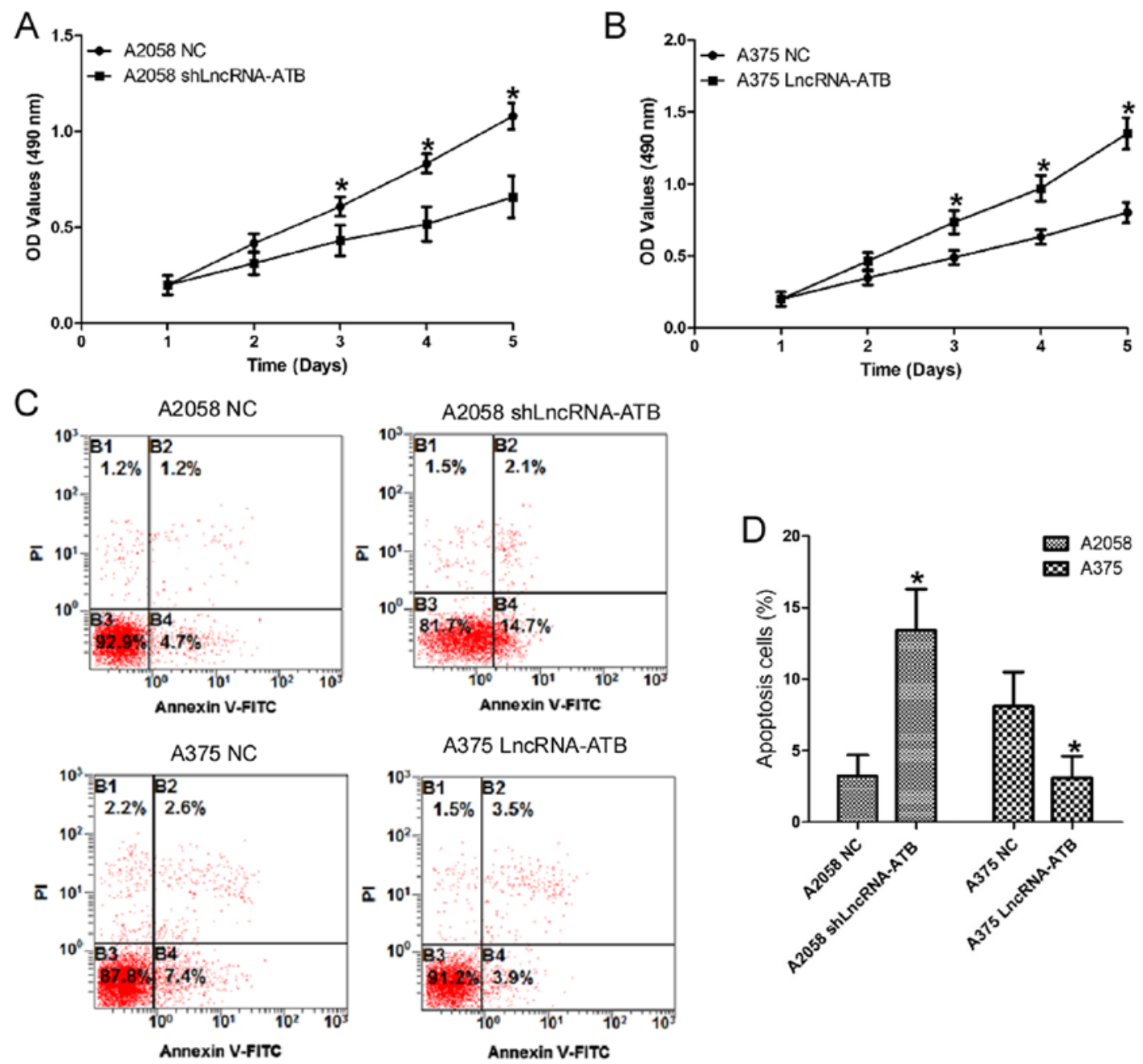

Figure 2. Effects of lncRNA-ATB on the cell proliferation and apoptosis of MM cells. (A) The effects of lncRNA-ATB shRNA on the proliferation of A2058 cells were detected by CCK-8 assays. (B) Effects of lncRNA-ATB on the proliferation of A375 cells were detected by CCK-8 assays. (C) Effects of IncRNA-ATB on the cellular apoptosis of MM cells were detected by flow cytometry using an Annexin V/PI kit, and (D) the results were quantified. Data are from three experiments and are presented as the mean \pm standard deviation. ${ }^{*} \mathrm{P}<0.05$ vs. respective NC group (Student's t-test). MM, malignant melanoma; lncRNA, long noncoding RNA; shRNA, short hairpin RNA; NC, negative control; PI, propidium iodide; FITC, fluorescein isothiocyanate; OD, optical density; CCK-8, cell counting kit-8; ATB, activated by transforming growth factor- $\beta$.

These results demonstrated that miR-590-5p was also able to directly bind to lncRNA-ATB at specific recognition sites. A previous study reported miR-590-5p may function as a tumor suppressing miRNA in A375 cells (24). In addition, it may inhibit the cell migration and invasion of A375 by directly targeting YAP1. Thus, the present study investigated the effects of lncRNA-ATB on the YAP1 protein expression level. The western blotting results demonstrated that the expression of YAP1 protein was significantly downregulated in A2058 cells transfected with shLncRNA-ATB. By contrast, ectopic expression of lncRNA-ATB in A375 cells resulted in increased YAP1 protein expression levels (Fig. 6G and H).

\section{Discussion}

In the present study, it was demonstrated that lncRNA-ATB, which had been reported to be activated by TGF- $\beta$ (25), was upregulated in A375 cells compared with human melanocytes. In addition, it was observed that lncRNA-ATB was able to promote $\mathrm{MM}$ cell proliferation, migration and invasion in vitro, and MM tumor growth in vivo. Furthermore, it was demonstrated that lncRNA-ATB attenuated cell cycle arrest and inhibited cellular apoptosis in MM cells. Finally, the present study provided the first evidence, to the best of our knowledge, that lncRNA-ATB functions as a ceRNA to enhance YAP1 expression by competitively sponging miR-590-5p in MM cells. Taken together, these results demonstrated that IncRNA-ATB may function as a ceRNA to upregulate YAP1 expression, and promote cell proliferation and invasion, in MM cells by sponging miR-590-5p to reduce the binding of miR-590-5p to YAP1.

IncRNA-ATB has been reported to be upregulated in a number of types of cancer, including papillary thyroid cancer (26), renal cell carcinoma (27) and gastric cancer (28). IncRNA-ATB was identified as a TGF- $\beta$-activated lncRNA (25); thus, the function of IncRNA-ATB may be consistent with TGF- $\beta$ pathways in different tumors, although certain lncRNAs, including HOX transcript antisense RNA, serve entirely opposite function in different types of cancer cells $(29,30)$. It is possible that lncRNA-ATB is an example of this type of non-coding RNA. However, according to previous studies $(25,31)$, it was noted that IncRNA-ATB serves an 
A

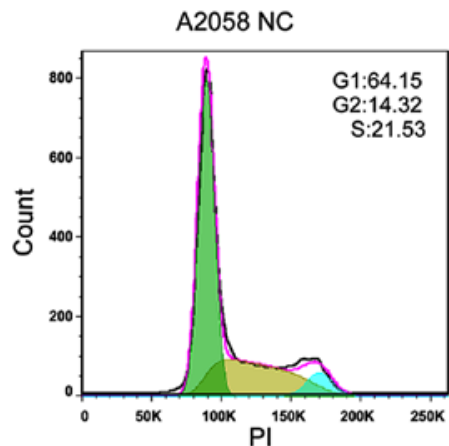

B

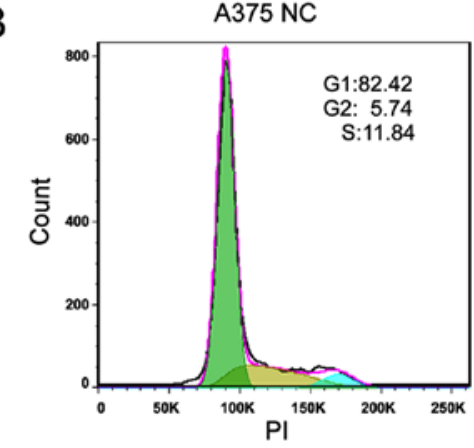

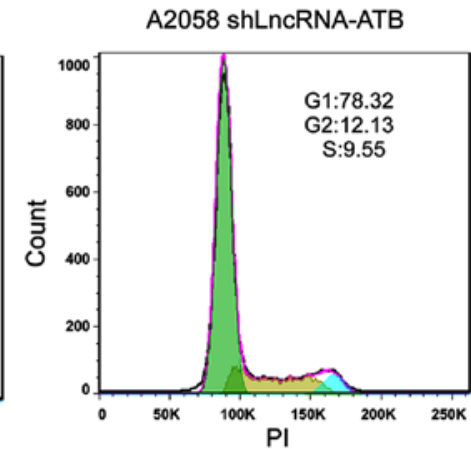

A375 LncRNA-ATB

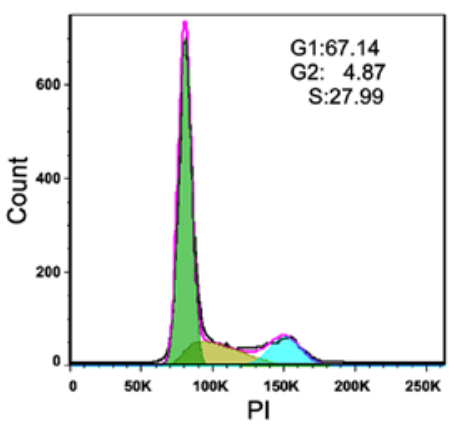

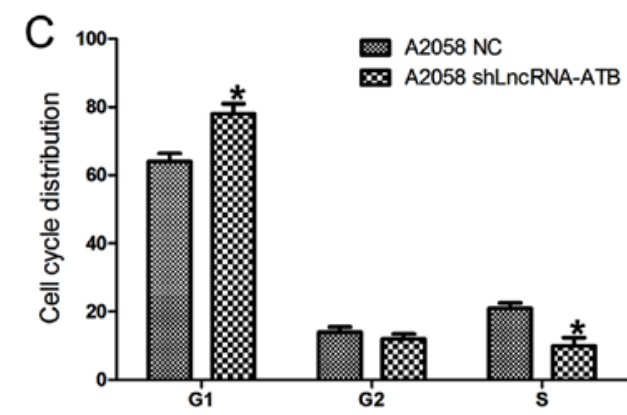

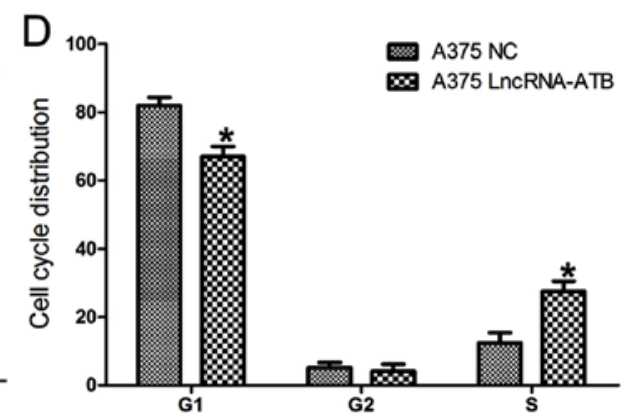

Figure 3. Effects of lncRNA-ATB on the cell cycle distribution of malignant melanoma cells. (A) Effects of lncRNA-ATB shRNA on the cell cycle distribution of A2058 cells were detected by flow cytometry using PI. (B) Effects of 1ncRNA-ATB on the cell cycle distribution of A375 cells were detected by flow cytometry using PI. (C) Quantification of the results in A2058 cells. (D) Quantification of the results in A375 cells. Data are from three experiments and presented as mean $\pm \mathrm{SD} .{ }^{*} \mathrm{P}<0.05$ vs. respective $\mathrm{NC}$ group (Student's t-test). PI, propidium iodide; lncRNA, long noncoding RNA; shRNA, short hairpin RNA; ATB, activated by transforming growth factor- $\beta$; NC, negative control.

oncogenic role in the majority of types of cancers. In line with these previous studies, the present study identified that lncRNA-ATB was significantly upregulated in MM cell lines compared with normal human epidermal melanocyte cell lines. In non-small cell lung cancer, lncRNA-ATB promotes cellular apoptosis, and inhibits cell viability, cell migration and invasion (31). Furthermore, lncRNA-ATB was identified as a potential oncogene in osteosarcoma (32), glioma (33), prostate cancer (34) and colon cancer (35); the upregulation of lncRNA-ATB was able to promote carcinogenesis and progression in these cancer types. Notably, through searching electronic databases, a meta-analysis reported that IncRNA-ATB was associated with adverse clinical features, overall survival, progression-free survival and prognosis in human cancer (36). Studies have also confirmed that increased lncRNA-ATB expression is an independent prognostic predictor in a number of types of cancer, including non-small cell lung cancer (37), gastric cancer (38) and colorectal cancer (39).

To further determine the biological role of lncRNAs in $\mathrm{MM}$, gain or loss-of- function experiments were performed.
The results revealed that lncRNA-ATB promoted cell proliferation, migration and invasion, and attenuated cell cycle arrest in vitro. It was additionally demonstrated that knockdown of IncRNA-ATB was able to inhibit tumor growth in vivo. In addition to lncRNA-ATB, a number of other lncRNAs have been demonstrated to be potential oncogenes or tumor suppressors in MM, including homeobox A11-antisense (40), hepatocellular carcinoma upregulated EZH2-associated lncRNA (41) and colon cancer associated transcript 1 (42). In agreement with these studies, IncRNA-ATB was identified in the present study to be a potential oncogene in MM, and the critical roles of IncRNAs in the carcinogenesis and progression of MM were further confirmed. As it is difficult to perform gain-or-loss of function experiments using normal epidermal melanocytes, the present study did not investigate the role of IncRNA-ATB in HEMa-LP cells. Although lncRNA-ATB serves an important role in carcinogenesis, it was considered likely that the proliferation of HEMa-LP may not exhibit a marked alteration, due to the number of tumor suppressor genes in HEMa-LP cells to suppress the function of IncRNA-ATB. It was also observed that the basal 


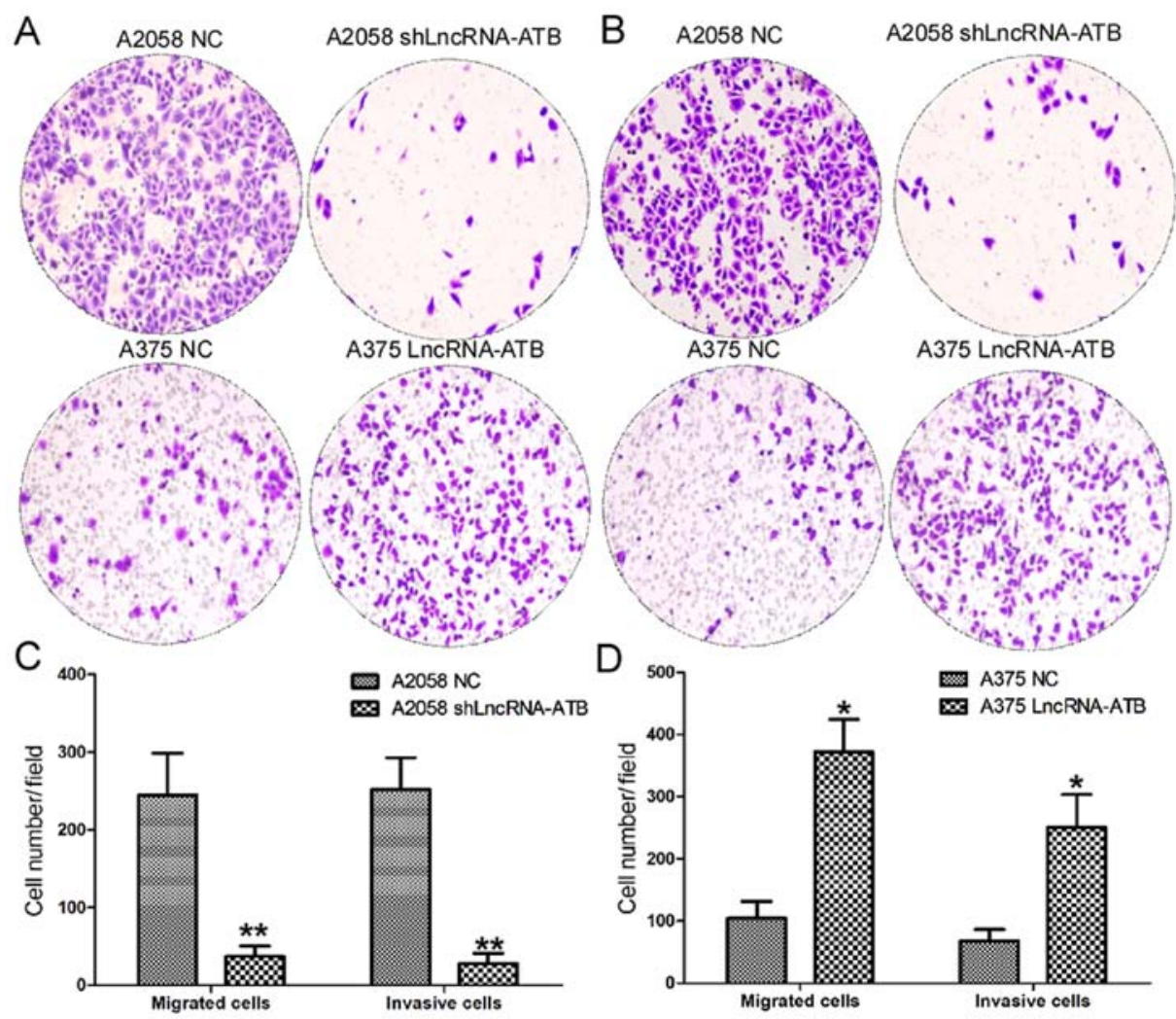

Figure 4. Effects of lncRNA-ATB on the cell migration and invasion of MM cells. (A) Effects of lncRNA-ATB shRNA on the cell migration of A2058 and A375 cells were detected by Transwell assays (magnification, x200). (B) Effects of lncRNA-ATB shRNA on the cell invasion of A2058 and A375 cells were detected by Transwell assays (magnification, x200). (C) Analysis of the migration and invasion data from A2058 cells. (D) Analysis of the migration and invasion data from A375 cells. Data are from three experiments and are presented as the mean \pm standard deviation. ${ }^{*} \mathrm{P}<0.05$ and ${ }^{* *} \mathrm{P}<0.01 \mathrm{vs}$. respective NC group (Student's t-test). NC, negative control; shRNA, short hairpin RNA; lncRNA, long noncoding RNA; ATB, activated by transforming growth factor- $\beta$.

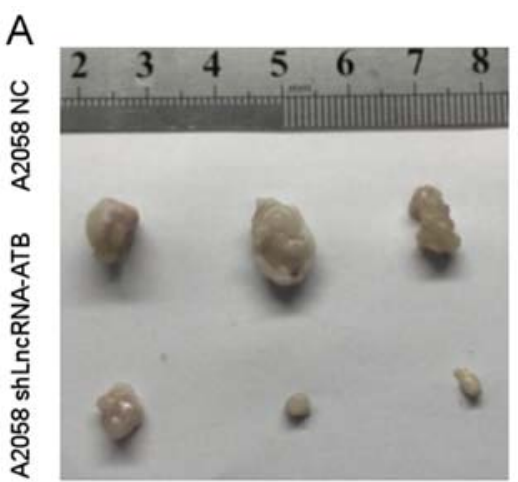

B
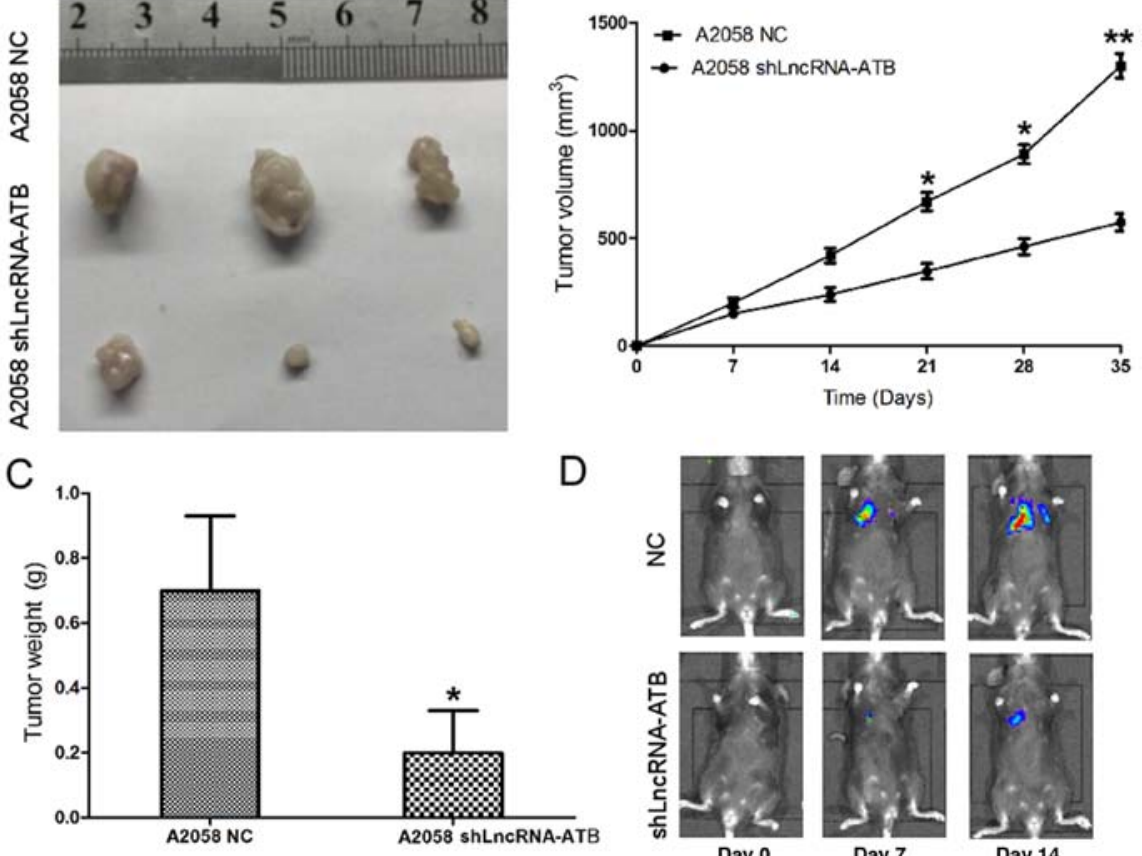

D

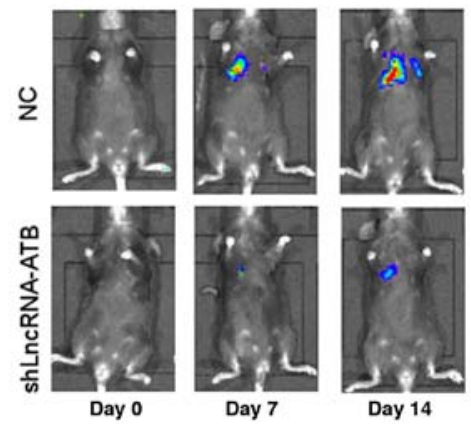

Figure 5. Effects of lncRNA-ATB on the tumorigenic ability and lung colonization of MM cells. (A) Tumors collected from the lncRNA-ATB shRNAluciferase groups and A2058 lncRNA-ATB NC-luciferase groups. (B) Tumor growth curve of A2058 lncRNA-ATB shRNA-luciferase cells and A2058 lncRNA-ATB NC-luciferase cells in nude mice. (C) Tumor weights of lncRNA-ATB shRNA-luciferase and A2058 lncRNA-ATB NC-luciferase groups at day 35. (D) Effects of lncRNA-ATB shRNA on lung metastasis were measured using a Xenogene IVIS Kinetic imaging system every 7 days subsequent to injecting B16/F10 lncRNA-ATB shRNA-luciferase cells and B16/F10 lncRNA-ATB NC-luciferase cells intravenously into C57/B6 mice. Data are from three experiments and are presented as the mean \pm standard deviation. ${ }^{*} \mathrm{P}<0.05$ vs. respective NC group (Student's t-test). NC, negative control; shRNA, short hairpin RNA; IncRNA, long noncoding RNA; ATB, activated by transforming growth factor- $\beta$. 

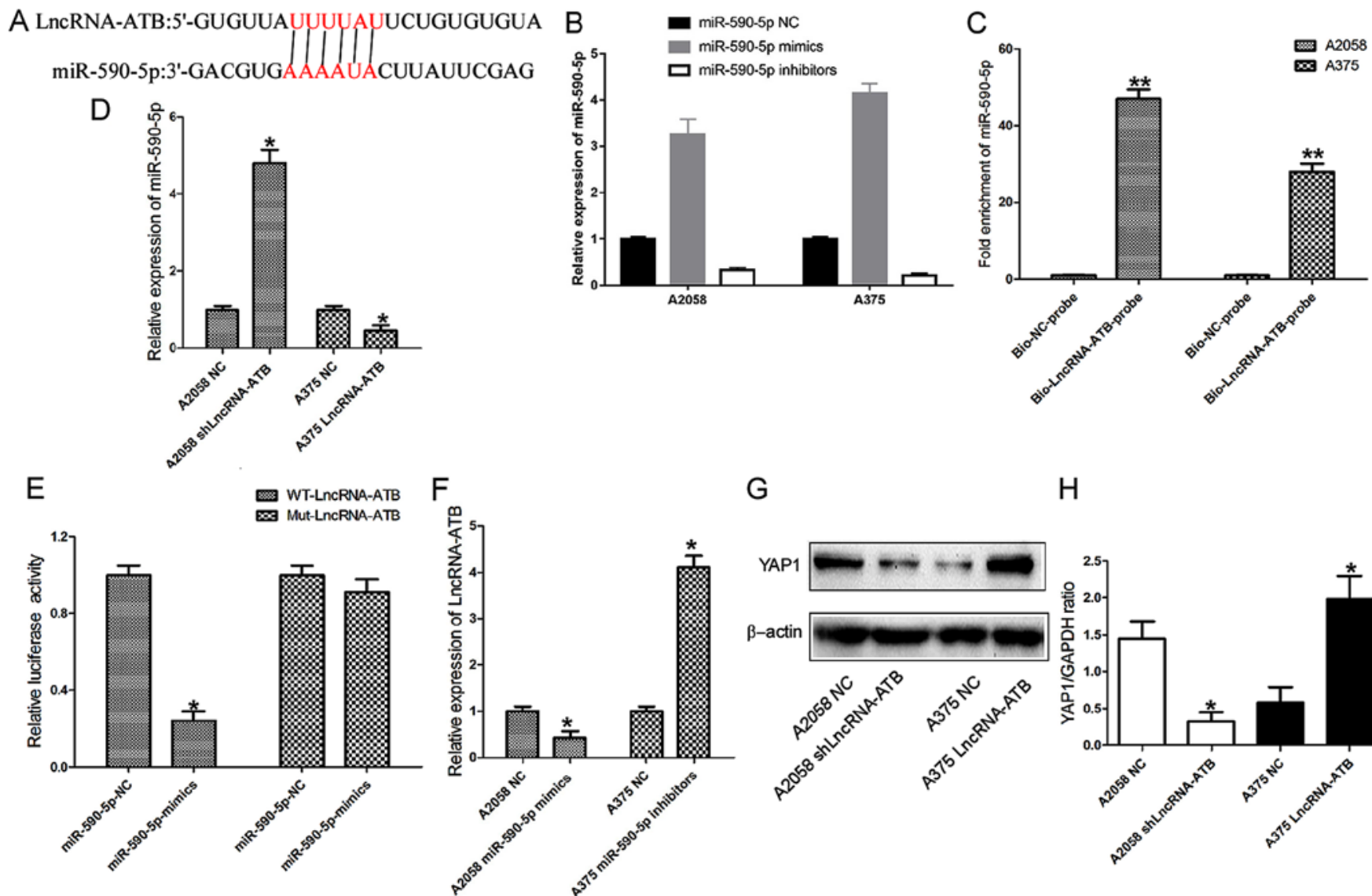

G

$\mathrm{H}$
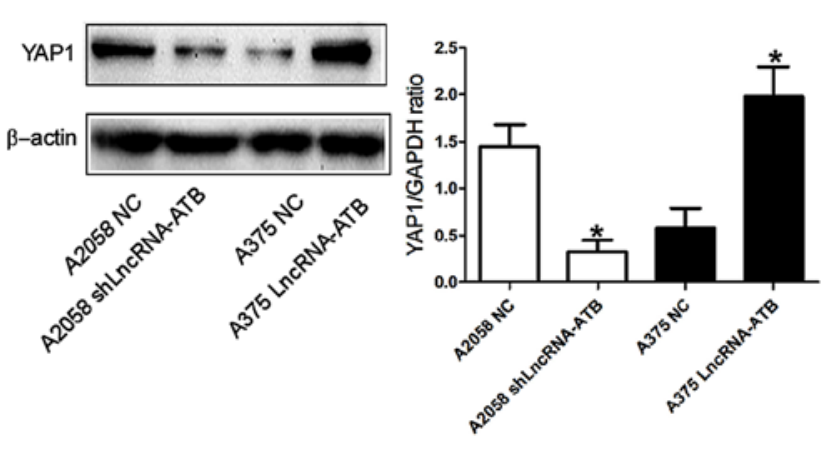

Figure 6. 1ncRNA-ATB sponges miR-590-5p to promote YAP1 expression in MM cells. (A) lncRNA-ATB and its putative binding sequence in miR-50-5p (B) Efficacy of miR-590-5p mimics or inhibitors in MM cells. (C) Relative expression of miR-590-5p in the same sample pulled down by biotinylated lncRNA-ATB and NC probe. (D) Relative expression of miR-590-5p in MM cells transfected with lncRNA-ATB shRNA and lncRNA-ATB overexpressing plasmid. (E) Relative luciferase activity in 293 cells transfected with WT or Mut lncRNA-ATB plasmid. (F) Relative expression of lncRNA-ATB in MM cells transfected with miR-590-5p mimics or inhibitors. (G) Immunoblotting analysis and (H) relative quantification of YAP1 expression levels in MM cells transfected with lncRNA-ATB shRNA or overexpressing plasmid. Data are from three experiments and are presented as the mean \pm standard deviation. ${ }^{*} \mathrm{P}<0.05$ and ${ }^{* *} \mathrm{P}<0.01$ vs. respective NC group (Student's t-test). MM, malignant melanoma; NC, negative control; shRNA, short hairpin RNA; IncRNA, long noncoding RNA; ATB, activated by transforming growth factor- $\beta$; WT, wild-type; Mut, mutant; YAP1, Yes associated protein 1; miR, microRNA; Bio, biotinylated.

measurements of A2058 cells and A375 cells with respect to the cell cycle, cell migration and cell invasion were different. There may be a number of reasons to account for this discrepancy. Firstly, the source of A2058 and A375 is different. Compared with A375, A2058 is a more invasive cell line. Thus, the number of migrated and invasive A2058 cells transfected with lncRNA-ATB NC was greater compared with the A375 cells transfected with lncRNA-ATB NC. Secondly, the different levels of lncRNA-ATB may be one of the factors accounting for the increased invasive ability of A2058 cells.

Recently, studies identified lncRNAs that were able to act as ceRNAs to interfere with miRNAs and their downstream pathways, which affect post-transcriptional regulation $(43,44)$. ceRNA regulatory networks are implicated in numerous biological processes in cancer, including tumorigenesis (45), epithelial-mesenchymal transition (46) and the invasion-metastasis cascade (47). For example, IncRNA metastasis associated lung adenocarcinoma transcript 1 is overexpressed in $\mathrm{MM}$ and upregulates the expression levels of matrix metallopeptidase 14 and snail family transcriptional repressor 1 by competitively sponging miR-22, thus promoting tumor growth and metastasis (48). Similarly, the lncRNA melanoma highly expressed competing endogenous IncRNA for miR-425 and
miR-489 also functions as a ceRNA to upregulate insulin like growth factor 1 and spindling 1 expression by sponging miR-425 and miR-489, thereby promoting tumor growth and metastasis in MM (49). IncRNA-ATB was also demonstrated to be a ceRNA in hepatocellular carcinoma, upregulating zinc finger E-box binding homeobox 1 and 2 expression, and promoting the invasion-metastasis cascade by competitively binding miR-200 (50). The present study further increased understanding of the ceRNA function of IncRNA-ATB. The potential miR-590-5p binding sites were identified in lncRNA-ATB transcripts, and it was demonstrated that lncRNA-ATB expression was negatively regulated by miR-590-5p. Notably, it was confirmed that lncRNA-ATB may function as a ceRNA by sponging miR-590-5p to upregulate YAP1 expression in MM cells.

In conclusion, the present study demonstrated that IncRNA-ATB is a potential oncogene in MM. IncRNA-ATB was able to promote the tumor growth and metastasis of MM cells in vivo and in vitro by sponging miR-590-5p, functionally releasing YAP1 mRNA transcripts that are normally targeted by miR-590-5p. The present study helped to reveal the regulatory mechanism of lncRNA-ATB in MM and may lead to novel therapeutic strategies for MM. 


\section{Acknowledgements}

Not applicable.

\section{Funding}

The present study was supported by Hospital Fund of the First Affiliated Hospital of Xi'an JiaoTong University (Xi'an, China; grant no. 2016QN-06).

\section{Availability of data and materials}

The datasets used and/or analyzed during the current study are available from the corresponding author on reasonable request.

\section{Authors' contributions}

LW conceived the experiments and drafted the manuscript. $\mathrm{KM}$ and $\mathrm{BL}$ conducted the experiments and helped to analyze the data. MD performed data analysis. XM, YZ and DH performed data analysis and revised the manuscript. All authors contributed to revise the manuscript and approved the final version for publication.

\section{Ethics approval and consent to participate}

Animal experiments were approved by and carried out according to the guidelines of the Ethics Committee of the First Affiliated Hospital of Xi'an Jiaotong University (Xi'an, China).

\section{Patient consent for publication}

Not applicable.

\section{Competing interests}

The authors declare that they have no competing interests.

\section{References}

1. Siegel RL, Miller KD and Jemal A: Cancer Statistics, 2017. CA Cancer J Clin 67: 7-30, 2017.

2. Eggermont AM, Spatz A and Robert C: Cutaneous melanoma. Lancet 383: 816-827, 2014.

3. Roukos DH: PLX4032 and melanoma: Resistance, expectations and uncertainty. Expert Rev Anticancer Ther 11: 325-328, 2011.

4. Balch CM, Gershenwald JE, Soong SJ, Thompson JF, Atkins MB Byrd DR, Buzaid AC, Cochran AJ, Coit DG, Ding S, et al: Final version of 2009 AJCC melanoma staging and classification. J Clin Oncol 27: 6199-6206, 2009.

5. Kondo Y, Shinjo K and Katsushima K: Long non-coding RNAs as an epigenetic regulator in human cancers. Cancer Sci 108 1927-1933, 2017.

6. Bhan A, Soleimani M and Mandal SS: Long noncoding RNA and cancer: A new paradigm. Cancer Res 77: 3965-3981, 2017.

7. Bolha L, Ravnik-Glavač M and Glavač D: Long noncoding RNAs as biomarkers in cancer. Dis Markers 2017: 7243968, 2017.

8. Zhao L, Sun H, Kong H, Chen Z, Chen B and Zhou M: The Lncrna-TUG1/EZH2 axis promotes pancreatic cancer cell proliferation, migration and EMT phenotype formation through sponging Mir-382. Cell Physiol Biochem 42: 2145-2158, 2017.

9. Zhang BY, Jin Z and Zhao Z: Long intergenic noncoding RNA 00305 sponges miR-136 to regulate the hypoxia induced apoptosis of vascular endothelial cells. Biomed Pharmacother 94: 238-243, 2017.
10. Chen Y, Peng Y, Xu Z, Ge B, Xiang X, Zhang T, Gao L, Shi H, Wang $C$ and Huang J: LncROR promotes bladder cancer cell proliferation, migration, and epithelial-mesenchymal transition. Cell Physiol Biochem 41: 2399-2410, 2017.

11. Wang C, Mao ZP, Wang L, Wu GH, Zhang FH, Wang DY and Shi JL: Long non-coding RNA MALAT1 promotes cholangiocarcinoma cell proliferation and invasion by activating PI3K/Akt pathway. Neoplasma 64: 725-731, 2017.

12. Yang $\mathrm{C}, \mathrm{Wu} \mathrm{D}$, Gao L, Liu X, Jin Y, Wang D, Wang $\mathrm{T}$ and Li X: Competing endogenous RNA networks in human cancer: Hypothesis, validation, and perspectives. Oncotarget 7: 13479-13490, 2016.

13. Tay Y, Rinn J and Pandolfi PP: The multilayered complexity of ceRNA crosstalk and competition. Nature 505: 344-352, 2014.

14. Guo LL, Song CH, Wang P, Dai LP, Zhang JY and Wang KJ: Competing endogenous RNA networks and gastric cancer. World J Gastroenterol 21: 11680-11687, 2015.

15. Richtig G, Ehall B, Richtig E, Aigelsreiter A, Gutschner T and Pichler M: Function and clinical implications of long non-coding RNAs in melanoma. Int J Mol Sci 18: E715, 2017.

16. Wang S, Fan W, Wan B, Tu M, Jin F, Liu F, Xu H and Han P: Characterization of long noncoding RNA and messenger RNA signatures in melanoma tumorigenesis and metastasis. PLoS One 12: e0172498, 2017.

17. Bian D, Gao C, Bao K and Song G: The long non-coding RNA NKILA inhibits the invasion-metastasis cascade of malignant melanoma via the regulation of NF-kB. Am J Cancer Res 7: 28-40, 2017.

18. Livak KJ and Schmittgen TD: Analysis of relative gene expression data using real-time quantitative PCR and the 2(-Delta Delta C(T)) method. Methods 25: 402-408, 2001.

19. Guide for the Care and Use of Laboratory Animals. National Academy Press, Washington (DC), 1996.

20. Rehmsmeier M, Steffen P, Hochsmann M and Giegerich R: Fast and effective prediction of microRNA/target duplexes. RNA 10: 1507-1517, 2004

21. RDevelopment CORE TEAM: R: A Language and Environment for Statistical Computing. R foundation for statistical computing, 2014. http://www.R-project.org/.

22. Tan YD and Xu H: A general method for accurate estimation of false discovery rates in identification of differentially expressed genes. Bioinformatics 30: 2018-2025, 2014.

23. Talantov D, Mazumder A, Yu JX, Briggs T, Jiang Y, Backus J, Atkins D and Wang Y: Novel genes associated with malignant melanoma but not benign melanocytic lesions. Clin Cancer Res 11: 7234-7242, 2005.

24. Wang L, Shi S, Zhou Y,Mu X,Han D, Ge R and Mu K: miR-590-5p inhibits A375 cell invasion and migration in malignant melanoma by directly inhibiting YAP1 expression. Xi Bao Yu Fen Zi Mian Yi Xue Za Zhi 33: 326-330, 2017 (In Chinese).

25. Shi SJ, Wang LJ, Yu B, Li YH, Jin Y and Bai XZ: LncRNA-ATB promotes trastuzumab resistance and invasion-metastasis cascade in breast cancer. Oncotarget 6: 11652-11663, 2015.

26. Fu XM, Guo W, Li N, Liu HZ, Liu J, Qiu SQ, Zhang Q, Wang LC, $\mathrm{Li} \mathrm{F}$ and $\mathrm{Li} \mathrm{CL}$ : The expression and function of long noncoding RNA lncRNA-ATB in papillary thyroid cancer. Eur Rev Med Pharmacol Sci 21: 3239-3246, 2017.

27. Qi JJ, Liu YX and Lin L: High expression of long non-coding RNA ATB is associated with poor prognosis in patients with renal cell carcinoma. Eur Rev Med Pharmacol Sci 21: 2835-2839, 2017.

28. Lei K, Liang X, Gao Y, Xu B, Xu Y, Li Y, Tao Y, Shi W and Liu J: Lnc-ATB contributes to gastric cancer growth through a MiR-141-3p/TGF $\beta 2$ feedback loop. Biochem Biophys Res Commun 484: 514-521, 2017

29. Kim HJ, Lee DW, Yim GW, Nam EJ, Kim S, Kim SW and Kim YT: Long non-coding RNA HOTAIR is associated with human cervical cancer progression. Int J Oncol 46: 521-530, 2015

30. Chen Y, Bian Y, Zhao S, Kong F and Li X: Suppression of PDCD4 mediated by the long non-coding RNA HOTAIR inhibits the proliferation and invasion of glioma cells. Oncol Lett 12: 5170-5176, 2016.

31. Cao Y, Luo X, Ding X, Cui S and Guo C: LncRNA ATB promotes proliferation and metastasis in A549 cells by down-regulation of microRNA-494. J Cell Biochem: Apr 25, 2018 (Epub ahead of print). doi: 10.1002/jcb.26894.

32. Han F, Wang C, Wang Y and Zhang L: Long noncoding RNA ATB promotes osteosarcoma cell proliferation, migration and invasion by suppressing miR-200s. Am J Cancer Res 7: 770-783, 2017. 
33. Ma CC, Xiong Z, Zhu GN, Wang C, Zong G, Wang HL, Bian EB and Zhao B: Long non-coding RNA ATB promotes glioma malignancy by negatively regulating miR-200a. J Exp Clin Cancer Res 35: 90, 2016.

34. Xu S, Yi XM, Tang CP, Ge JP, Zhang ZY and Zhou WQ: Long non-coding RNA ATB promotes growth and epithelial-mesenchymal transition and predicts poor prognosis in human prostate carcinoma. Oncol Rep 36: 10-22, 2016.

35. Yue B, Qiu S, Zhao S, Liu C, Zhang D, Yu F, Peng Z and Yan D: LncRNA-ATB mediated E-cadherin repression promotes the progression of colon cancer and predicts poor prognosis. J Gastroenterol Hepatol 31: 595-603, 2016.

36. Fan YH, Ji CX, Xu B, Fan HY, Cheng ZJ and Zhu XG: Long noncoding RNA activated by TGF-beta in human cancers: A meta-analysis. Clin Chim Acta 468: 10-16, 2017.

37. Ke L, Xu SB, Wang J, Jiang XL and Xu MQ: High expression of long non-coding RNA ATB indicates a poor prognosis and regulates cell proliferation and metastasis in non-small cell lung cancer. Clin Transl Oncol 19: 599-605, 2017.

38. Saito T, Kurashige J, Nambara S, Komatsu H, Hirata H, Ueda M, Sakimura S, Uchi R, Takano Y, Shinden Y, et al: A long noncoding RNA activated by transforming growth factor- $\beta$ is an independent prognostic marker of gastric cancer. Ann Surg Oncol 22 (Suppl 3): S915-S922, 2015.

39. Iguchi T, Uchi R, Nambara S, Saito T, Komatsu H, Hirata H, Ueda M, Sakimura S, Takano Y, Kurashige J, et al: A long noncoding RNA, lncRNA-ATB, is involved in the progression and prognosis of colorectal cancer. Anticancer Res 35: 1385-1388, 2015.

40. Lu Q, Zhao N, Zha G, Wang H, Tong Q and Xin S: LncRNA HOXA11-AS exerts oncogenic functions by repressing p21 and miR-124 in uveal melanoma. DNA Cell Biol 36: 837-844, 2017.

41. Zhao H, Xing G, Wang Y, Luo Z, Liu G and Meng H: Long noncoding RNA HEIH promotes melanoma cell proliferation, migration and invasion via inhibition of $m i R-200 b / a / 429$. Biosci Rep 37: BSR20170682, 2017.

42. Lv L, Jia JQ and Chen J: LncRNA CCAT1 upregulates proliferation and invasion in melanoma cells via suppressing miR-33a. Oncol Res 26 201-208, 2018.
43. $\mathrm{Qu} \mathrm{J}$, Li M, Zhong $\mathrm{W}$ and $\mathrm{Hu} \mathrm{C}$ : Competing endogenous RNA in cancer: A new pattern of gene expression regulation. Int J Clin Exp Med 8: 17110-17116, 2015.

44. Qi X, Zhang DH, Wu N, Xiao JH, Wang X and Ma W: ceRNA in cancer: Possible functions and clinical implications. J Med Genet 52: 710-718, 2015.

45. Cui B, Li B, Liu Q and Cui Y: IncRNA CCAT1 promotes glioma tumorigenesis by sponging miR-181b. J Cell Biochem 118: 4548-4557, 2017.

46. Lv M, Zhong Z, Huang M, Tian Q, Jiang R and Chen J: IncRNA $\mathrm{H} 19$ regulates epithelial-mesenchymal transition and metastasis of bladder cancer by miR-29b-3p as competing endogenous RNA. Biochim Biophys Acta 1864: 1887-1899, 2017.

47. Wang H, Huo X, Yang XR, He J, Cheng L, Wang N, Deng X, Jin $\mathrm{H}$, Wang $\mathrm{N}$, Wang $\mathrm{C}$, et al: STAT3-mediated upregulation of lncRNA HOXD-AS1 as a ceRNA facilitates liver cancer metastasis by regulating SOX4. Mol Cancer 16: 136, 2017.

48. Luan W, Li L, Shi Y, Bu X, Xia Y, Wang J, Djangmah HS, Liu X, You Y and Xu B: Long non-coding RNA MALAT1 acts as a competing endogenous RNA to promote malignant melanoma growth and metastasis by sponging miR-22. Oncotarget 7 : 63901-63912, 2016.

49. Chen X, Dong H, Liu S, Yu L, Yan D, Yao X, Sun W, Han D and Gao G: Long noncoding RNA MHENCR promotes melanoma progression via regulating miR-425/489-mediated PI3K-Akt pathway. Am J Transl Res 9: 90-102, 2017.

50. Yuan JH, Yang F, Wang F, Ma JZ, Guo YJ, Tao QF, Liu F, Pan W, Wang TT, Zhou CC, et al: A long noncoding RNA activated by TGF- $\beta$ promotes the invasion-metastasis cascade in hepatocellular carcinoma. Cancer Cell 25: 666-681, 2014.

This work is licensed under a Creative Commons Attribution-NonCommercial-NoDerivatives 4.0 International (CC BY-NC-ND 4.0) License. 